\title{
$O$ teocentrismo da mensagem de Jesus: uma introdução ao significado do Reino de Deus no pensamento de Joseph Ratzinger
}

\author{
The teocentrism of the message of Jesus: \\ an introduction to the meaning of the Kingdom of God in the \\ thought of Joseph Ratzinger
}

Luis Carlos Pereira Santos da Silva

\section{Resumo}

A pergunta sobre o significado do Reino de Deus se relaciona diretamente com a questão sobre o Jesus histórico e constitui um elemento central para a cristologia na discussão teológica moderna. Naturalmente, isto se justifica porque o tema do Reino de Deus penetra toda pregação de Jesus. Também J. Ratzinger não ficou indiferente a essa discussão. Assim, ainda que brevemente, o presente trabalho se empenhará na identificação das bases ou pressupostos sobre os quais ele reflete sobre este conceito e pretende explorar qual o significado do Reino de Deus para ele. Deseja-se, assim, demonstrar que, tanto na sua obra teológica, como durante seu magistério pontifício, no que se refere especificamente à essa temática, a mensagem de Jesus tem em Deus mesmo a sua referência absoluta, é derivada de Deus mesmo e em Deus encontra seu destino e sua plena realização, uma vez que, como ele mesmo afirma, não é possível distinguir em Jesus a função da pessoa; nele essa diferença perde a sua razão de ser. A pessoa é a função e a função é a pessoa.

Palavras-chave: Reino de Deus. Cristologia. Joseph Ratzinger. 


\section{Abstract}

The question about the meaning of the Kingdom of God relates directly to the question about the historical Jesus and constitutes a central element for Christology in the modern theological discussion. Of course, this is justified because the theme of the Kingdom of God permeates all preaching of Jesus. Also J. Ratzinger was not indifferent to this discussion. Thus, although briefly, the present work will strive to identify the bases or assumptions on which it reflects on this concept and intends to explore what the meaning of the Kingdom of God is for it. It is thus desired to demonstrate that both in his theological work and during his pontifical magisterium, in what refers specifically to this subject, the message of Jesus has in God his absolute reference, is derived from God himself and in God finds his destiny and his full realization, since, as he himself affirms, it is not possible to distinguish in Jesus the function of the person; in him this difference loses his reason for being. The person is the function and the function is the person.

Keywords: Kingdom of God. Christology. Joseph Ratzinger.

\section{Introdução}

A pergunta sobre o significado do Reino de Deus se relaciona diretamente com a questão sobre o Jesus histórico ${ }^{1}$ e constitui um elemento central para a cristologia na discussão teológica moderna. A questão é de tal modo relevante que, mais recentemente, autores como G. Lohfink, R. Schnackenburg, W. Kasper, G. Theissen, A. Merz, R. Fabris, B. Forte, J. P. Meier e J. A. Pagola, por exemplo, se debruçaram sobre o assunto. ${ }^{2}$

\footnotetext{
${ }^{1}$ A questão sobre o Jesus histórico tem sido amplamente estudada desde o séc. XVIII e, a partir de então, diversos autores, entre os quais David Friedrich Strauss, Albert Schweitzer, Martin Kahler, Adolf von Harnack, Rudolf Bultmann, Marcus J. Borg, elaboraram teses sobre o tema. Mais recentemente, apenas para citar algumas obras, pode-se conferir o desenvolvimento desta problemática em CROSSAN, J. D., O Jesus histórico; MEIER, J. P., Um judeu marginal; SEGALLA, G., A pesquisa do Jesus histórico; PAGOLA, J. A., Jesus; THEISSEN, G.; MERZ, A., Jesus histórico; e ZUURMOND, R., Procurais o Jesus histórico?

${ }^{2}$ Os autores citados desenvolveram a questão do Reino de Deus, respectivamente, em LOHFINK, G., Jesus de Nazaré; SCHNACKENBURG, R., Reino y Reinado de Dios; KASPER, W., Jesus, el Cristo; THEISSEN, G.; MERZ, A., Jesus histórico; FABRIS, R.; Jesus de Nazaré; FORTE, B., Jesus de Nazaré; MEIER, J. P., Um judeu marginal; e PAGOLA, J. A., Jesus.
} 
Naturalmente, isto se justifica porque "o tema do Reino de Deus penetra toda pregação de Jesus". ${ }^{3}$

Nesse sentido, é possível verificar que, desde o advento da pesquisa histórico-crítica, se iniciou um movimento de produção e publicação de diversas reconstruções sobre Jesus. Também se tornou comum observar que o modo como a categoria do Reino de Deus foi compreendida varia desde um símbolo da luta pela queda dos poderes opressores, numa lógica políticorevolucionária, até como uma realidade meramente moral, interpretada como um fruto da mansidão religiosa do "mestre nazareno". Muitas dessas reconstruções sobre Jesus, inclusive, a depender da perspectiva considerada por seus autores, tornaram-se relativamente contrastantes entre si.

Será, assim, neste panorama hermenêutico significativamente amplo, no tocante à missão e mensagem de Jesus, que se desenvolverão as pesquisas modernas referentes ao Jesus histórico e, consequentemente, a respeito do conteúdo e significado de seu anúncio sobre o Reino de Deus (pesquisas estas que seguem, em pleno desenvolvimento, até os dias atuais). Também, no contexto desta discussão, é possível vislumbrar, a partir de alguns dos escritos de Joseph Ratzinger / Bento XVI, a interpretação que ele faz sobre o significado do Reino de Deus.

De maneira resumida, pode-se dizer que se verifica o seguinte no seu pensamento: ele busca apresentar o Jesus dos Evangelhos como o Jesus real; vale-se do relacionamento de dependência vinculante entre o querigma apostólico-eclesial pós-pascal e a pregação pré-pascal de Jesus; e, por fim, orienta-se por uma identificação da mensagem do Reino de Deus com o seu mensageiro, isto é, a própria pessoa de Jesus de Nazaré. Conforme indicação sua, "nesse sentido torna-se presente nele e por ele, aqui e agora, o Reino de Deus, que se aproximou". ${ }^{4}$ A temática é complexa e muitas são as questões imbricadas com esse tema. Isto, por si somente, manifesta sua relevância. Evidentemente, não se presume que serão elas aqui abordadas em sua totalidade.

$\mathrm{O}$ presente texto foi elaborado, fundamentalmente, com a pretensão de se ocupar, por meio de revisão bibliográfica, apenas de três questões. Nesse sentido, se tem como objetivo principal buscar, especificamente, em algumas obras de Joseph Ratzinger / Bento XVI, a identificação do elemento nuclear do anúncio de Jesus sobre o Reino de Deus e, ainda, tentar apresentar seu significado, conforme a hermenêutica que ele realizou. Antes disso, no entanto,

\footnotetext{
${ }^{3}$ RATZINGER, J., Jesus de Nazaré, p. 70.

${ }^{4}$ RATZINGER, J., Jesus de Nazaré, p. 68.
} 
inicialmente, se pretende verificar qual lugar ocupam a categoria e a realidade do Reino de Deus na vida pública de Jesus, a partir de alguns autores. Para isso, serão utilizadas, ainda que brevemente, algumas reflexões de G. Vermès, J. A. Pagola, John P. Meier e R. Schnackenburg que, assim como J. Ratzinger, se dedicaram à questão.

\section{O lugar do Reino de Deus na vida pública de Jesus}

Jesus iniciou seu ministério depois de ser batizado por João (Mt 4,12-17; Lc 4,14-15). A partir de então, como, em geral, nos informam os evangelhos, os seus gestos e as suas palavras passaram a orbitar em torno do anúncio do Reino de Deus, que constitui uma ideia central de sua pregação. Assim, fica explicitado, inclusive, porque, entre os autores que se debruçam sobre o problema do Jesus histórico, há significativo consenso de que o Reino de Deus é, pelo menos, uma temática importante da mensagem de Jesus.

A este respeito, apenas para citar alguns autores mais contemporâneos, G. Vermès, por exemplo, assinala que "pela simples frequência das expressões 'Reino de Deus' e 'Reino dos Céus' é razoável inferir que os conceitos que refletem desempenharam papel importante no ensinamento de Jesus". ${ }^{5}$ É também, nesse sentido, que o mesmo autor, embora questione a originalidade de Jesus quanto ao tema do Reino de Deus na sua comparação com a doutrina preservada em fontes judaicas paralelas, ainda, acrescenta:

Esta afirmação simples representa o terreno comum da especialidade contemporânea do Novo Testamento. Assim, a primeira fase do capítulo introdutório de Theologie des Neuen Testaments (p.3) de Rudolf Bultmann, apresenta o "Reino de Deus" como o "conceito dominante" ("der beherrschende Begriff") da pregação de Jesus. Christopher Rowland vê nele um "pilar fundamental" (Christian Origins, 133) e Norman Perrin, o "aspecto central" do ensinamento de Jesus (Rediscovering, 54). Para E. P. Sanders, é um dos tópicos "mais discutidos" do Novo Testamento (Jesus and Judaism, 123). Por sua vez, Anthony Harvey (Constraints, 86), ecoando Joachim Jeremias (NT Theology, 32-34), enfatiza a natureza sem paralelo das expressões que a ele se referem. ${ }^{6}$

\footnotetext{
${ }^{5}$ VERMÈS, G., A religião de Jesus, o judeu, p. 113.

${ }^{6}$ VERMÈS, G., A religião de Jesus, o judeu, p. 113.
} 
Também J. A. Pagola observa a acentuada preponderância do tema do Reino de Deus dentre às causas das quais Jesus se ocupava. Para ele, o projeto de Jesus somente se torna compreensível, se a sua interpretação assume como liame o Reino de Deus, seu conceito e sua realidade. No seu entendimento, "ninguém duvida desta informação que nos proporcionam as fontes: Jesus foi andando de povoado em povoado e de aldeia em aldeia proclamando e anunciando a boa notícia do Reino de Deus". ${ }^{7}$ É ele também quem assinala o seguinte:

Sem temor de equivocar-nos, podemos dizer que a causa à qual Jesus dedica daqui em diante seu tempo, suas forças e sua vida inteira é o que ele chama de Reino de Deus. É, sem dúvida, o núcleo central de sua pregação, sua convicção mais profunda, a paixão que anima toda a sua atividade. Tudo aquilo que ele diz e faz está a serviço do Reino de Deus. Tudo adquire sua unidade, seu verdadeiro significado e sua força apaixonante a partir dessa realidade. O Reino de Deus é a chave para captar o sentido que Jesus dá à sua vida. ${ }^{8}$

Evidentemente, muitos são os autores que se dedicaram à reflexão sobre o lugar do Reino de Deus na vida pública de Jesus. Entre eles podemos citar, ainda, J. P. Meier, para quem "o Reino de Deus era, no mínimo um componente significativo da mensagem de Jesus", 9 condição que, segundo ele mesmo indica, pode ser atestada seja pelo critério da múltipla confirmação das fontes, seja pelo critério da descontinuidade. ${ }^{10} \mathrm{O}$ mesmo pode ser dito de R. Schnackenburg, para quem a doutrina de Cristo abarcava seguramente muito mais do que imediatamente se referia ao Reino de Deus, mas tinha na mensagem do Reino de Deus - mensagem nova, peculiar e excitante - o núcleo de sua pregação. ${ }^{11}$

Nas palavras de J. Ratzinger, enfim, "o conteúdo central do Evangelho diz: o Reino de Deus está próximo" "12 e, segundo a sua interpretação, essa é uma realidade de tal modo identificada com Jesus, sua pessoa e sua mensagem, que seu "anúncio forma realmente o centro da palavra e do ministério de Jesus". ${ }^{13}$ A relevância do tema do Reino de Deus para Jesus é, ainda, manifestada pela

\footnotetext{
${ }^{7}$ PAGOLA, J. A., Jesus, p. 115.

${ }^{8}$ PAGOLA, J. A, Jesus, p. 115.

${ }^{9}$ MEIER, J. P., Um judeu marginal, p. 10.

${ }^{10}$ MEIER, J. P., Um judeu marginal, p. 10.

${ }^{11}$ SCHNACKENBURG, R., Reino y Reinado de Dios, p. 65-68.

${ }^{12}$ RATZINGER, J., Jesus de Nazaré, p. 58.

${ }^{13}$ RATZINGER, J., Jesus de Nazaré, p. 58.
} 
incidência numerosa e a significativa frequência com que ele se utiliza dessa expressão ou de outras similares. Nesse sentido, segundo J. Ratzinger uma indicação estatística pode sublinhar isto: "a expressão Reino de Deus ocorre no conjunto do Novo Testamento 122 vezes; destas, encontra-se 99 vezes nos três Evangelhos Sinóticos e, destes, de novo, 90 pertencem às palavras de Jesus". ${ }^{14}$

$\mathrm{E}$, justamente, porque, como admite J. Ratzinger, o núcleo da mensagem de Jesus é o anúncio sobre o Reino de Deus, ou, pelo menos, porque esta seria uma ideia central de sua pregação (se comparada com outras das quais ele também se vale), alguns questionamentos vão orientar esta reflexão: qual seria o efetivo significado deste anúncio feito por Jesus? Porque sua proclamação sobre a realidade do Reino de Deus figura com tamanha relevância em sua vida pública? E, ainda, o mais importante, já que este é o objeto precípuo deste trabalho, o que constituiria, segundo o pensamento de J. Ratzinger, o aspecto central desta pregação de Jesus sobre o Reino de Deus?

$\mathrm{Na}$ perspectiva, então, de se buscar uma possível aproximação das respostas para as questões acima levantadas, a partir de agora, serão tomadas algumas noções das quais J. Ratzinger se vale em sua reflexão sobre o assunto, uma vez que, também ele, não ficou indiferente a essa discussão. Assim, se tentará refletir sobre aquilo que, segundo J. Ratzinger, estaria no centro da mensagem de Jesus, para, em seguida, se buscar evidenciar qual seria, também segundo o entendimento do autor, o real significado do Reino de Deus, conforme o anúncio de Jesus durante a sua vida pública.

\section{O teocentrismo da mensagem de Jesus}

O empreendimento da tarefa da identificação das bases ou pressupostos sobre os quais J. Ratzinger concebe o Reino de Deus, conforme anunciado por Jesus, deve ser realizado com alguma atenção. E um aspecto que não pode ser ignorado, mas, ao contrário, deve ser tido em elevada conta é que, para ele, "não é possível distinguir em Jesus a função da pessoa; nele essa diferença perde a sua razão de ser. A pessoa é a função e a função é a pessoa". ${ }^{15}$ De fato, para ele, não há qualquer vestígio de uma oposição ontológico-funcional em Jesus.

Ao que tudo indica, segundo J. Ratzinger propõe, Jesus desloca o acento do Reino para a figura de seu Deus e Pai, tanto que quando Jesus realiza sua pregação e opera o seu anúncio, essa realidade é atualizada, pois o Deus do

\footnotetext{
${ }^{14}$ RATZINGER, J., Jesus de Nazaré, p. 58.

${ }^{15}$ RATZINGER, J., Introdução ao cristianismo, p. 152.
} 
Reino age nas obras que são próprias de Jesus: "Ele mesmo é a obra de Deus em ação, sua chegada, seu reinar". ${ }^{16}$ Nesse sentido, sua mensagem é teológica, teocêntrica, ou, pelo menos, "teoreferenciada", nunca ideológica. A mensagem de Jesus sobre o Reino de Deus incide sobre a existência e a história humanas de modo integral e integrador. Fundamentalmente, Jesus fala de Deus e, nesse sentido, o teocentrismo da sua mensagem seria evidente.

Nesse aspecto, o caminho percorrido por Jesus, seus gestos realizados e as palavras por ele transmitidas durante a proclamação do Reino de Deus, não podem ser reduzidos simplesmente a um projeto pessoal, dissociado de sua mais profunda identidade de Filho de Deus encarnado ou coincidente com algum programa de cunho meramente político, social, revolucionário ou moral, como, por exemplo, propunham muitos de seus contemporâneos ou como, diversas vezes e segundo diversas interpretações, se pretendeu fazer ao longo da história. Na verdade, "o Reino de Deus não significa, na boca de Jesus, uma coisa ou lugar, mas o agir de Deus no presente". ${ }^{17}$

A mensagem de Jesus, que tem em Deus mesmo a sua referência absoluta, é derivada de Deus mesmo e em Deus encontra seu destino e sua plena realização e, portanto, para J. Ratzinger, nada justifica que se substitua o núcleo central do anúncio de Cristo, isto é, a sua própria pessoa. Nesse sentido, o Reino de Deus não pode, então, ser reduzido a um conceito, a uma doutrina ou mesmo a atividades programáticas que, eventualmente, permitam alterações ou livres interpretações do anúncio realizado por Jesus. De fato, para J. Ratzinger, devese tomar por irrenunciável a absoluta unidade entre a pessoa de Jesus, o Filho de Deus, e a sua mensagem, o Reino de Deus.

A este respeito, ele escreve o seguinte:

Por isto podemos traduzir diretamente a expressão programática de Mc 1,15: "O Reino de Deus está perto, com: Deus está perto. Surge aqui, outra vez, a conexão com Jesus, com sua pessoa: ele próprio é a proximidade de Deus. Onde ele está, está o Reino de Deus. Neste sentido devemos modificar a frase de Loisy: Prometeu-se o Reino de Deus e veio Jesus. Somente assim compreenderemos corretamente o paradoxo da promessa e do cumprimento. ${ }^{18}$

\footnotetext{
${ }^{16}$ RATZINGER, J., Compreender a Igreja hoje, p. 13.

${ }^{17}$ RATZINGER, J., Compreender a Igreja hoje, p. 14.

${ }^{18}$ RATZINGER, J., Compreender a Igreja hoje, p. 14.
} 
Numa sua reflexão sobre a oração do Senhor fica latente a preocupação que tem em demonstrar que a mensagem de Jesus é, fundamentalmente, centrada em Deus mesmo. Para ele, não serão, por exemplo, nem o piedoso desejo inspirado pela promessa de uma terra de delícias nem, ao menos, o automatismo funcional apresentado pelas utopias de uma sociedade sem classes que determinarão o bem do ser humano. ${ }^{19}$ Ao invés disso, ele sugere o seguinte, quando se debruça sobre o pedido do Reino de Deus que Jesus faz na oração do Pai Nosso:

Com este pedido reconhecemos, antes de mais nada, o primado de Deus: onde Ele não está, nada pode ser bom. Onde Deus não é visto, o homem arruína-se e arruína-se o mundo. Neste sentido, o Senhor nos diz: procurai antes de mais nada o Reino (de Deus) e a sua justiça, que tudo mais vos será dado (Mt 6,33). Com esta expressão é estabelecida uma ordem de prioridades para a ação humana, para a nossa atitude no cotidiano. ${ }^{20}$

É de se notar, que mesmo o acento antropológico da pregação de Jesus, do qual é derivada sua manifesta intolerância a qualquer sinal de mal que ameace a vida humana e suas necessidades fundamentais, tem no Deus cujo Reino Ele anuncia e realiza, sua irrenunciável referência. E, a este respeito, ele insiste no seguinte:

Jesus não nos fornece uma receita tão simples. Mas ele estabelece - como foi dito - uma decisiva prioridade. "Reino de Deus" quer dizer soberania de Deus, e isso significa: é aceito o critério da sua vontade. Essa vontade cria justiça, à qual pertence que nós damos a Deus o seu Direito e assim a medida para encontrar o direito entre os homens. ${ }^{21}$

Ora, este aspecto do teocentrismo da mensagem de Jesus - deve-se considerar - assume uma tal relevância na reflexão de J. Ratzinger acerca do tema do Reino de Deus, que parece acompanhá-lo mesmo durante seu magistério pontifício. Em certo sentido, isso fica evidenciado quando, por exemplo, já no primeiro ano de seu pontificado, durante seu Discurso à Cúria Romana, em 22 de dezembro de 2006, ele afirma que "ao falar de Deus, tocamos também precisamente o assunto que, na pregação terrena de Jesus, constituía o seu interesse central. O tema fundamental dessa pregação é o

\footnotetext{
${ }^{19}$ RATZINGER, J., Jesus de Nazaré, p. 135.

${ }^{20}$ RATZINGER, J., Jesus de Nazaré, p. 134.

${ }^{21}$ RATZINGER, J., Jesus de Nazaré, p. 135.
} 
domínio de Deus, o Reino de Deus". ${ }^{22}$ Noutra ocasião, agora, através na Carta Encíclica Spe Salvi, também podem ser encontrados ecos referentes a essa problemática no pontificado de Bento XVI, quando no referido texto são apresentadas as seguintes reflexões:

A época moderna desenvolveu a esperança da instauração de um mundo perfeito que, graças aos conhecimentos da ciência e a uma política cientificamente fundada, parecia tornar-se realizável. Assim, a esperança bíblica do Reino de Deus foi substituída pela esperança do reino do homem, pela esperança de um mundo melhor que seria o verdadeiro Reino de Deus [...] Todavia, não há dúvida de que um Reino de Deus realizado sem Deus - e por conseguinte um reino somente do homem resolve-se inevitavelmente no fim perverso de todas as coisas. ${ }^{23}$

\section{O significado do Reino de Deus}

É interessante perceber que a noção de J. Ratzinger sobre o significado do Reino de Deus é mantida no diálogo estabelecido com diferentes autores das mais diversas épocas e tradições. No capítulo sobre o Evangelho do Reino de Deus, que se encontra no primeiro volume de sua obra Jesus de Nazaré, ele confronta este seu posicionamento com autores patrísticos (especialmente, Orígenes, a quem, inclusive, ele atribui essa noção da autobasileia), medievais e modernos; quanto a estes últimos J. Ratzinger menciona, por exemplo, A. von Harnack, J. Weiss, A. Schweitzer, R. Bultmann, J. Moltmann e E. Bloch. ${ }^{24}$

Nesse ponto, com algum pesar na reflexão que faz, J. Ratzinger conclui, então, que o teocentrismo da mensagem de Jesus teria sido substituído por uma interpretação secularista do Reino que, como tarefa das religiões, deveria se manter centrada apenas na paz, justiça e no respeito pela criação, pois o que conta, segundo ele mesmo indica, seria, única e exclusivamente, a organização do mundo. ${ }^{25}$ No entanto, para ele, somente isto não bastaria para compreender o profundo significado do Reino de Deus, uma vez que, aquilo que estaria em jogo na reflexão sobre essa categoria, como dito acima, é mesmo o discurso sobre Deus.

Também a consideração de algumas de suas obras, como a sua Introdução ao Cristianismo, a trilogia Jesus de Nazaré (particularmente em seu

\footnotetext{
${ }^{22}$ BENTO XVI, PAPA. Discurso aos membros da Cúria e da Prelazia romana para a apresentação das felicitações natalinas (22 de dezembro de 2006), 31.

${ }^{23}$ SS 23.30 .

${ }^{24}$ RATZINGER, J., Jesus de Nazaré, p. 58-64.

${ }^{25}$ RATZINGER, J., Jesus de Nazaré, p. 62-63.
} 
primeiro volume) e, ainda, a publicação de suas conferências no livro Compreender a Igreja Hoje, por exemplo, possibilita atestar que essa discussão figura como tema caro para ele, tratado com atenção e que tem como fio condutor a interpretação de que o núcleo do anúncio do Reino de Deus, conforme realizado por Jesus (Mc 1,14-15), não é outra realidade, senão, a própria pessoa de Jesus. De fato, esta sutileza de sua interpretação é marcante na obra de J. Ratzinger. Nesse sentido, se o núcleo central daquilo que Jesus anuncia é o próprio Deus e o significado do Reino de Deus é manifestado na pessoa de Jesus, segundo ele indica, "Jesus é o Reino de Deus em pessoa". ${ }^{26}$

Visto sob essa perspectiva, no entanto, J. Ratzinger pondera que "não se trata simplesmente da presença física de Jesus, na qual estaria o 'Reino', mas sim no seu agir que acontece no Espírito Santo. Neste sentido torna-se presente n'Ele e por Ele, aqui e agora, o Reino de Deus, 'que está a chegar"'. ${ }^{27}$ Outra questão importante é que, para ele, somente é possível compreender o tema do Reino de Deus a partir da totalidade da pregação de Jesus. A mensagem de Jesus, nesse sentido, não é sectária, partidária ou parcial. Ele alerta, "seu discurso sobre Deus é sempre central, mas precisamente porque Jesus mesmo - o Filho - é Deus, então toda a sua pregação é mensagem do seu próprio mistério, a cristologia, isto é, discurso acerca da presença de Deus na sua própria ação e no seu próprio ser". ${ }^{28}$

\section{Conclusão}

Muito já se empreendeu e refletiu sobre aquilo que pretendia Jesus durante a sua proclamação sobre o Reino de Deus. Evidentemente, se tem plena consciência de que o presente trabalho, até pelas características que o envolvem, tentou apenas oferecer uma reflexão, de caráter introdutório, a este importante tema cristológico, também presente na sua produção teológica.

J. Ratzinger fez uma escolha na elaboração de sua cristologia. Em certo sentido, pode-se dizer que, para ele, a pessoa de Jesus permaneceria obscura, irreal e inexplicável sem seu fundamento em Deus. Aliás, ele mesmo afirma que, "vê Jesus a partir de sua comunhão com o Pai, a qual é o centro autêntico de sua personalidade, sem a qual nada se pode compreender e a partir da qual Ele se torna presente para nós hoje". ${ }^{29}$

${ }^{26}$ RATZINGER, J., Jesus de Nazaré, p. 137.

${ }^{27}$ RATZINGER, J., Jesus de Nazaré, p. 68.

${ }^{28}$ RATZINGER, J., Jesus de Nazaré, p. 70.

${ }^{29}$ RATZINGER, J., Jesus de Nazaré, p. 11. 
Em certo sentido, esta hermenêutica que J. Ratzinger faz sobre a missão e a mensagem de Jesus, impõe-se como um imperativo irrenunciável, que deseja elucidar, entre outras coisas, o modo como os discípulos de Jesus conseguirão se manter fiéis à sua identidade, poderão manter vivas sua relevância eclesial e social ao longo da história. Também não lhes permite usurpar do cristianismo a absoluta referência a Deus, conforme manifestada nas opções de Jesus e, ainda, mantémlhes alertas quanto ao risco de confundirem outras doutrinas e/ou ideologias com o evangelho do Reino de Deus anunciado por Jesus.

Assim, torna-se significativo o reforço de que qualquer causa que pretenda tornar secundária ou até mesmo substituível este que é o núcleo do cristianismo deveria ser evitada, seja porque pode abrir espaço para uma visão equivocada do que seja o Reino de Deus, seja por que, na verdade, desconsidera que "a pessoa de Jesus é a sua doutrina e a sua doutrina é ele próprio". ${ }^{30}$ Mais uma vez, torna-se, assim, oportuna a menção ao Discurso do Papa Bento XVI à Cúria Romana, em 22 de dezembro de 2006:

Na palavra "Reino de Deus", a palavra "Deus" é o genitivo subjetivo. Isto significa: Deus não é um acréscimo ao "Reino" que talvez se poderia também ignorar. Deus é o sujeito. Reino de Deus significa dizer na realidade: Deus reina. Ele mesmo está presente e é determinante para os homens no mundo. Ele é o sujeito, e onde falta este sujeito nada permanece da mensagem de Jesus. Por isso Jesus diz-nos: O Reino de Deus não vem de modo que se possa, por assim dizer, pôr-se na beira da estrada a observar a sua chegada. "Está no meio de vós!" (cf. Lc 17,20s.). Ele desenvolve-se onde é realizada a vontade de Deus. Está presente onde há pessoas que se abrem à sua chegada e assim deixam que Deus entre no mundo. Por isso é o Reino de Deus em pessoa: o homem no qual Deus está no meio de nós e através do qual nós podemos tocar Deus, aproximar-nos de Deus. Onde isto acontece, o mundo salva-se. ${ }^{31}$

Pelo caminho percorrido até aqui, durante as reflexões apresentadas ao longo do presente trabalho, espera-se poder ter esclarecido que há, no pensamento de J. Ratzinger, uma evidente preocupação em resguardar a referência ao primado da iniciativa divina, que irrompeu, de maneira absolutamente nova, no anúncio do Reino de Deus realizado por Jesus e que,

\footnotetext{
${ }^{30}$ RATZINGER, J., Introdução ao cristianismo, p. 154.

${ }^{31}$ BENTO XVI, PAPA. Discurso aos membros da Cúria e da Prelazia romana para a apresentação das felicitações natalinas (22 de dezembro de 2006), 31.
} 
portanto, jamais poderá ser relativizada ou, muito menos, substituída, por quem pretenda se colocar como continuador desta sua missão.

Ora, também Jesus teve diante de si, naquele contexto da Palestina do primeiro século, outras esperanças sobre o Reino de Deus. Muitos textos inter e neotestamentários oferecem vivos testemunhos dos rumos tomados pela esperança no interior de Israel e, ainda, das atitudes assumidas e das interpretações que se foram construindo sobre a realidade do Reino de Deus. Todavia seja pela consciência de sua mais íntima identidade, seja pela maneira original com que atuou as suas escolhas, pode-se dizer que ele jamais se permitiu agir sem uma mínima referência ao seu Deus e Pai. E, fundamentalmente, nessa percepção parece residir a contribuição de J. Ratzinger para o cristianismo contemporâneo.

Evidentemente, no anúncio e atualização do Reino de Deus, conforme anunciado por Jesus, há outras implicações a serem consideradas. Não se está ignorando isso. Estas, porém, deverão ser aprofundadas num outro trabalho, num outro momento. Por ora, espera-se que as presentes reflexões aqui apresentadas, a partir de algumas obras importantes de J. Ratzinger / Bento XVI, possam, de alguma forma, colaborar na reflexão teológica que se faz acerca do tema do Reino de Deus, pelo menos quanto a recordação e referência a Deus. E esta, certamente, constituiu uma significativa preocupação deste autor, na medida em que, para ele, "o grande problema do Ocidente é o esquecimento de Deus: é um esquecimento que se difunde". ${ }^{32}$

\section{Referências bibliográficas}

BENTO XVI, PP. Carta Encíclica Spe Salvi: sobre a esperança cristã. São Paulo: Paulinas, 2007.

BENTO XVI, PP. Discurso aos membros da Cúria e da Prelazia romana para a apresentação das felicitações natalinas (22 de dezembro de 2006): AAS 99 (2007).

CROSSAN, J. D. O Jesus histórico: a vida de um camponês judeu do mediterrâneo. Rio de Janeiro: Imago, 1994.

FABRIS, R. Jesus de Nazaré: história e interpretação. São Paulo: Loyola, 1998.

\footnotetext{
${ }^{32}$ BENTO XVI, PAPA. Discurso aos membros da Cúria e da Prelazia romana para a apresentação das felicitações natalinas (22 de dezembro de 2006), 31.
} 
FORTE, B. Jesus de Nazaré: história de Deus, Deus da história. Ensaio de uma cristologia como história. São Paulo: Paulinas, 1985.

KASPER, W. Jesús, El Cristo. 12. ed. Salamanca: Sígueme, 2006.

LOHFINK, G. Jesus de Nazaré: O que Ele queria? Quem Ele era? Petrópolis: Vozes, 2015.

MEIER, J. P. Um judeu marginal: repensando o Jesus histórico. Rio de Janeiro: Imago, 1997. v. II (Livro II - Mensagem).

PAGOLA, J. A. Jesus: aproximação histórica. Petrópolis, RJ: Vozes, 2014.

RATZINGER, J. Compreender a Igreja hoje: vocação para a comunhão. Petrópolis: Vozes, 1992.

RATZINGER, J. Introdução ao cristianismo: preleções sobre o símbolo apostólico com um novo ensaio introdutório. São Paulo: Ed. Loyola, 2005.

RATZINGER, J. Jesus de Nazaré: do batismo no Jordão à transfiguração. São Paulo: Planeta do Brasil, 2007. v.1.

SCHNACKENBURG, R. Reino y Reinado de Dios: estudo bíblico-teológico. Madrid: Edciones Fax, 1967.

SEGALLA, G. A pesquisa do Jesus histórico. São Paulo: Edições Loyola, 2013.

THEISSEN, G.; MERZ, A. Jesus histórico: um manual. São Paulo: Loyola, 2002.

VERMES, G. A religião de Jesus, o judeu. Rio de Janeiro: Imago, 1995.

ZUURMOND, R. Procurais o Jesus histórico? São Paulo: Edições Loyola, 1998.

\section{Luis Carlos Pereira Santos da Silva}

Mestrando em Teologia pela Pontifícia Universidade Católica do Rio de Janeiro Rio de Janeiro / RJ - Brasil E-mail: lucarlos.silva@gmail.com

Recebido em: 25/09/18

Aprovado em: 18/12/18 